\title{
MECANISMOS DE AÇÃO DO EXTRATO AQUOSO DE Piper amalago EM CÉLULAS MERISTEMÁTICAS DE Lactuca sativa
}

\author{
Thammyres de Assis Alves ${ }^{1}$ \\ Maikon Keoma da Cunha Henrique ${ }^{2}$ \\ Rondinelle Giordane Costa ${ }^{3}$ \\ Thayllon de Assis Alves ${ }^{4}$ \\ Milene Miranda Praça-Fontes ${ }^{5}$
}

Resumo: Para manutenção da segurança alimentar o uso de agrotóxicos tem aumentado em todo o mundo, sendo o Brasil o seu maior consumidor desde 2009. Porém, os danos ambientais e à saúde humana, causados por essas substâncias sintéticas, tem provocado preocupações. Uma forma de amenizar o uso dos agrotóxicos é substituí-los totalmente ou em partes por compostos naturais, encontrados em plantas. Piper amalago é uma espécie que possui diferentes compostos químicos em sua constituição, tais como: alcaloides, amidos, terpenos e esteroides, o que determina nas suas diferentes atividades biológicas. Em virtude da sua constituição química, essa espécie é indicada para estudos de alelopatia. Assim, o presente trabalho objetivou avaliar o potencial mutagênico do extrato aquoso de $P$. amalago através de bioensaio em Lactuca sativa. Para isso, análises de fitotoxicidade e citotoxicidade foram realizadas. Os dados obtidos foram submetidos ao teste de Dunnett com $5 \%$ de significância. Os resultados demonstram o potencial mutagênico do extrato aquoso de P. amalago em L. sativa, bem como, seus mecanismos de ação: clastogênicos e aneugênicos.

Palavras-chave: Alelopatia; Alface; Bioherbicida; Citotoxicidade.

\footnotetext{
${ }^{1}$ Mestranda em Genética e Melhoramento/Universidade Federal do Espírito Santo, Centro de Ciências Agrárias e Engenharias, Alegre/ES, Brasil. E-mail: thammyresalves@gmail.com.

2 Engenharia Florestal/Universidade Federal do Espírito Santo, Centro de Ciências Agrárias e Engenharias, Alegre/ES, Brasil. E-mail: maikond2@gmail.com.

${ }^{3}$ Mestrando em Genética e Melhoramento/Universidade Federal do Espírito Santo, Centro de Ciências Agrárias e Engenharias Alegre/ES, Brasil. E-mail: rondgiocosta@gmail.com.

4 Agronomia/Universidade Federal do Espírito Santo, Centro de Ciências Agrárias e Engenharias, Alegre/ES, Brasil. E-mail: thayllonalves@gmail.com.

${ }^{5}$ Professora Adjunta/Universidade Federal do Espírito Santo, Centro de Ciências Exatas, Naturais e da Saúde CCENS -UFES/Departamento de Biologia, Alegre/ES, Brasil. E-mail: milenemiranda@yahoo.com.br.
} 